\title{
COMPARATIVE STUDY OF CONVENTIONAL CONTROL TECHNIQUES FOR A DC-DC BUCK CONVERTER
}

\author{
${ }^{1}$ Shubham Kankurte, ${ }^{1}$ Soujanya K and ${ }^{2}$ Shama Ravichandran \\ ${ }^{1}$ UG student, EEE department, M. S. Ramaiah \\ University of Applied Sciences, Bangalore, India; \\ ${ }^{2}$ Assistant professor, EEE department, M. S. \\ Ramaiah University of Applied Sciences, India. \\ Email: $\{$ shamamsruas@gmail.com $\}$
}

\begin{abstract}
In this paper, conventional controllers like P, I, PID are designed for a DC-DC buck converter. The purpose of the controller is to maintain the output voltage. A comparative study of the control techniques is carried out. The overall system response is analyzed based on the performance and robustness. The usefulness of the control technique is tested by changing the reference voltage, introducing disturbances in the input voltage and parameters of the buck converter. Simulation results validate the efficacy of the conventional controllers.
\end{abstract}

Key Words - Conventional Controller, Buck Converter, Voltage Control.

\section{Introduction}

DC-DC converters are used to change one level of voltage to another level. There are various types of DC-DC converter. Buck converter is a basic type of DC-DC converter that converts the input $\mathrm{DC}$ voltage to a lower level of output DC voltage [1-3]. Buck converters are commonly used in switched mode power supplies. They are also used in electric vehicles. Due to its wide application, it's important to regulate the output voltage of a buck converter. It can be regulated using voltage control and current control methods $[4,5]$. In this work, voltage control method is used for controlling the output voltage. This is done by comparing the output voltage of the buck converter with a reference voltage which in turn generates an error signal that is fed to the conventional controller. Conventional controller design requires a transfer function model. Design of transfer function for a DC-DC converter is available in literature [6].

Various control techniques namely sliding mode control [7], internal mode control [8], $\mathrm{H} \infty$ control [9], adaptive control [10], predictive control [11] and PI/PID control [12] are reported in literature for the control of DCDC converters. Also, two loop control techniques $[13,14]$ are available. Though various techniques are available, the most conventional and easy one to design is a PID controller. Hence it is most commonly used in industrial applications. There are varieties of control actions available namely Proportional (P), Integral (I) and Derivative (D) control action. The combination of all three actions results in robust performance.

In this paper, basic knowledge of root locus is used for tuning the controller parameters to achieve the desired performance specifications. A comparative study of the three conventional control techniques for a DC-DC buck converter is carried out here. In addition, the performance of the closed loop system is evaluated for changes in input voltage, reference voltage and parameters of the buck converter. The brief outline of this paper is as follows: In section 1 a survey on the existing control techniques available for converters are given. Section 2 details the mathematical modelling of the buck converter followed by the conventional controller design in section 3. Simulation results are explained in section 4 and conclusion is available in section 5 .

\subsection{Buck converter mathematical model}

The basic buck converter model includes one switch (MOSFET), freewheeling diode, inductor and capacitor connected in parallel to the load resistor as shown below in Fig. 1. The operation of buck converter includes two states ON state and OFF state.

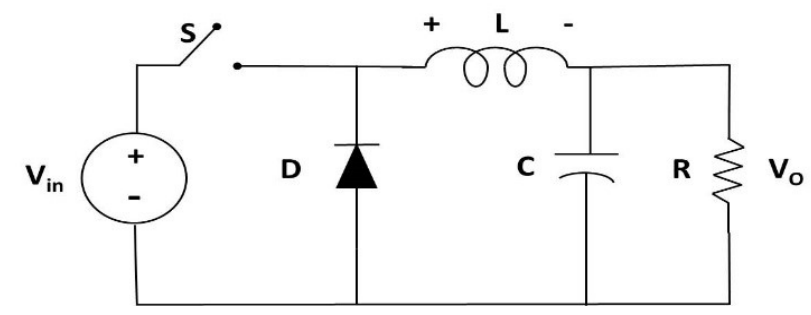

Fig. 1. Basic model of Buck converter 
Footnotes are indicated within the text by an asterisk sign in superscript ${ }^{*}$. It is used only for author information.

\subsection{ON state model}

In ON state of the buck converter operation the switch is ON. The freewheeling diode will be acting as reverse bias which means the diode switch is open. By applying KVL to the loop we get the equations for inductor current and output voltage as given in equations (1), (2) respectively.

$$
\begin{aligned}
& \frac{V_{i n}-V_{C}}{L}=\frac{d i_{L}}{d t} \\
& \frac{d V_{c}}{d t}=\frac{i_{L}}{C}-\frac{V_{C}}{R C}
\end{aligned}
$$

\subsection{OFF state model}

In OFF state operation the switch is OFF (Open). The freewheeling diode will be acting as forward bias which means the diode switch is closed. By applying KVL to the loop and rearranging the equations appropriately we get the equations for inductor current and output voltage as in (3), (4).

$$
\begin{gathered}
\frac{-V_{O}}{L}=\frac{d i_{L}}{d t} \\
\frac{d V_{C}}{d t}=\frac{i_{L}}{C}-\frac{V_{C}}{R C}
\end{gathered}
$$

\subsection{Transfer function}

Combining inductor current and output voltage equations during ON state and OFF state we arrive at (5) and (6).

$\frac{\mathrm{di}_{\mathrm{L}}}{\mathrm{dt}}=\frac{1}{\mathrm{~L}}\left[\left(\mathrm{~V}_{\mathrm{in}}-\mathrm{V}_{\mathrm{c}}\right) \mathrm{d}+\left(-\mathrm{V}_{\mathrm{c}}\right)(1-\mathrm{d})\right]=\frac{\mathrm{V}_{\mathrm{in}}}{\mathrm{L}} \mathrm{d}-\frac{\mathrm{V}_{\mathrm{c}}}{\mathrm{L}}$

$\frac{\mathrm{dV}_{\mathrm{c}}}{\mathrm{dt}}=\frac{1}{\mathrm{C}}\left[\left(\mathrm{i}_{\mathrm{L}}-\frac{\mathrm{V}_{\mathrm{C}}}{\mathrm{R}}\right) \mathrm{d}+\left(\mathrm{i}_{\mathrm{L}}-\frac{\mathrm{V}_{\mathrm{c}}}{\mathrm{R}}\right)(1-\mathrm{d})\right]=\frac{\mathrm{i}_{\mathrm{L}}}{\mathrm{C}}-\frac{\mathrm{V}_{\mathrm{C}}}{\mathrm{RC}}$

(6)

Here $\mathrm{i}_{\mathrm{L}}$ and $\mathrm{V}_{\mathrm{c}}$ are state variables $\mathrm{x}_{1}$ and $\mathrm{x}_{2}$ respectively. State equations with the assigned state variables are given below.

Equation of inductor current:

$$
\frac{\mathrm{dx}_{1}}{\mathrm{dt}}=\left(-\frac{1}{\mathrm{~L}}\right) \mathrm{x}_{2}+\frac{\mathrm{V}_{\mathrm{in}}}{\mathrm{L}} \mathrm{u}
$$

Equation of capacitor voltage:

$$
\frac{\mathrm{dx}_{2}}{\mathrm{dt}}=\left(\frac{1}{\mathrm{C}}\right) \mathrm{x}_{1}-\frac{1}{\mathrm{RC}} \mathrm{x}_{2}
$$

Next step is to determine the transfer function. The transfer function of the buck converter is given in equation (9)

$$
G_{P}(s)=\frac{Y(s)}{U(s)}=\left(\frac{\left(\frac{V_{\text {in }}}{L C}\right)}{\left(s^{2}+\left(\frac{1}{R C} s\right)+\frac{1}{L C}\right)}\right)
$$

\section{Conventional controller design}

\subsection{Open loop buck converter response}

In this section the open loop response of buck converter is shown in Fig. 2. The time domain performance specifications are given in Table 1. Fig. 3 shows the bode response of the open loop buck converter. From the response gain margin (GM), phase margin (PM) and stability aspects of the open loop buck converter can be determined. Here the GM is $\infty$ and PM is $0.91^{\circ}$. From Fig. 3, we can see that PM is positive and is very small. For a good performance a PM between $30^{\circ}$ and $60^{\circ}$ is require and the gain margin should be $>6 \mathrm{~dB}$. In the subsequent section a controller is added to improve the overall stability of the system.

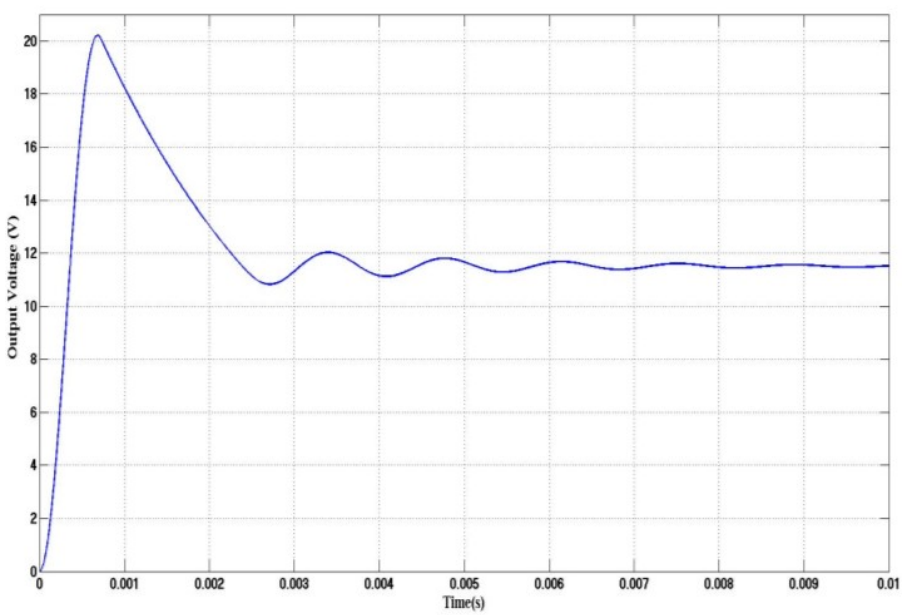

Fig. 2. Open loop response 
Table 1

Open loop time response parameters

\begin{tabular}{|l|l|l|l|l|}
\hline $\begin{array}{l}\text { Rise time } \\
(\mathrm{s})\end{array}$ & $\begin{array}{l}\text { Settling } \\
\text { time }(\mathrm{s})\end{array}$ & $\begin{array}{l}\% \\
\text { Overshoot }\end{array}$ & $\begin{array}{l}\text { Peak } \\
\text { Time } \\
(\mathrm{s})\end{array}$ & $\begin{array}{l}\text { Steady } \\
\text { state } \\
\text { error }\end{array}$ \\
\hline $2.34 \times 10^{-4}$ & 0.022 & 88.7 & 22.6 & 0.3 \\
\hline
\end{tabular}

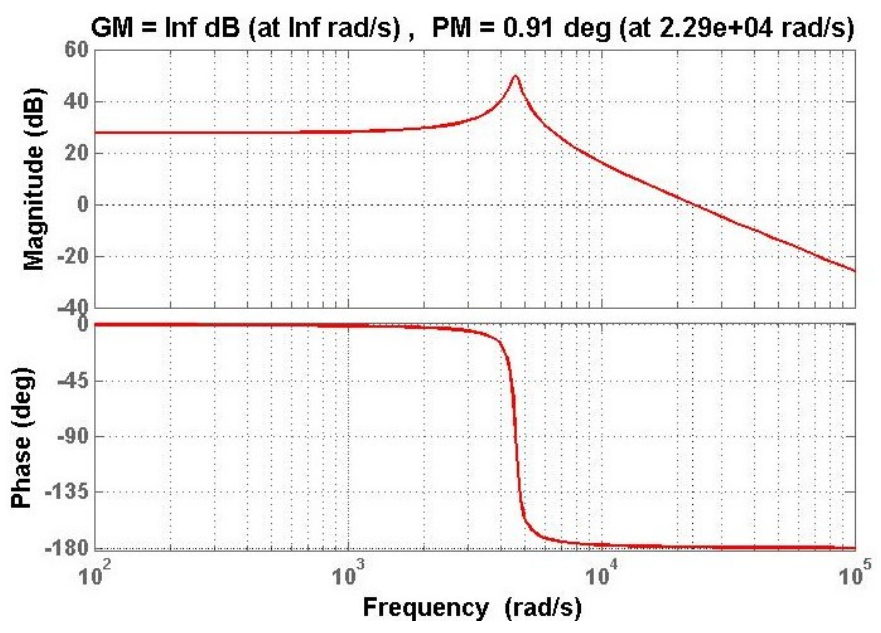

Fig. 3. Bode diagram

\subsection{Closed loop transfer function (CLTF)}

The general block diagram of the closed loop system incorporating a conventional controller is shown in Fig. 4. It has a reference voltage of $24 \mathrm{~V}$ given as input to the error detector and an output voltage of $12 \mathrm{~V}$. Here buck converter is the plant. The overall output is fed back to the error detector and compared with the reference voltage to generate an error signal that is given to the controller. The parameters of the buck converter are given as follows: capacitance $\mathrm{C}=220 \mu \mathrm{F}$, load Resistance $\mathrm{R}=13 \Omega$, switching frequency $\mathrm{F}_{\mathrm{SW}}=100 \mathrm{kHz}$, duty ratio $\mathrm{d}=0.5$, inductance $\mathrm{L}=216 \mu \mathrm{H}$.

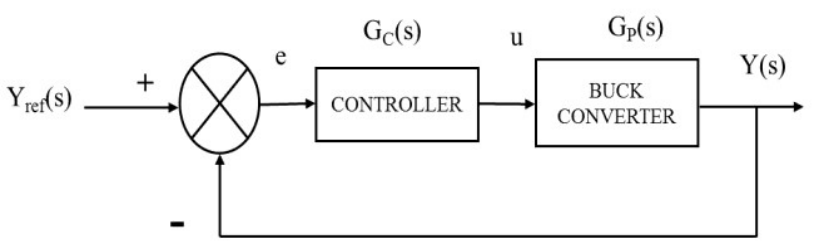

Fig. 4. Block Diagram

From Fig. 4, we arrive at the CLTF as given in (10)

$\frac{Y(s)}{Y_{\text {ref }}(s)}=\frac{G_{P}(s) G_{C}(s)}{1+G_{P}(s) G_{C}(s)}$

(10)

Substituting (9) in (10), we get the CLTF of a buck converter with a conventional controller $\mathrm{G}_{\mathrm{C}}(\mathrm{s})$ as given in (11)
$\frac{\mathrm{Y}}{\mathrm{Y}_{\text {ref }}}=\left(\frac{\mathrm{G}_{\mathrm{C}} \frac{\mathrm{V}_{\text {in }}}{\mathrm{LC}}}{\left(\mathrm{s}^{2}+\left(\frac{1}{\mathrm{RC}^{2}}\right) s+\frac{1}{\mathrm{LC}}+\mathrm{G}_{\mathrm{C}} \frac{\mathrm{V}_{\text {in }}}{\mathrm{LC}}\right)}\right)$

Substituting the controller TF in (11) we will arrive at the CLTF for the 3 control techniques as given in Table 2 .

Table 2

CLTF of buck converter

\begin{tabular}{|c|c|}
\hline $\begin{array}{l}\text { T } \\
\mathbf{y} \\
\mathbf{p} \\
\mathrm{e}\end{array}$ & CLTF of Buck converter \\
\hline $\mathrm{P}$ & $\left(\frac{\mathrm{K}_{\mathrm{p}} \frac{\mathrm{V}_{\text {in }}}{\mathrm{LC}}}{\left(\mathrm{s}^{2}+\left(\frac{1}{\mathrm{RC}^{2}}\right) \mathrm{s}+\frac{1}{\mathrm{LC}}+\mathrm{K}_{\mathrm{p}} \frac{\mathrm{V}_{\text {in }}}{\mathrm{LC}}\right)}\right)$ \\
\hline I & $\left(\frac{\frac{\mathrm{V}_{\text {in }}}{\mathrm{LC}} \mathrm{K}_{\mathrm{i}}}{\left(\mathrm{s}^{3}+\left(\frac{\mathrm{s}^{2}}{\mathrm{RC}^{2}}\right)+\frac{1}{\mathrm{LC}} \mathrm{s}+\frac{\mathrm{V}_{\text {in }}}{\mathrm{LC}} \mathrm{K}_{\mathrm{i}}\right)}\right)$ \\
\hline $\begin{array}{l}\text { P } \\
\text { I } \\
D\end{array}$ & $\frac{\mathrm{V}_{\text {in }}}{\mathrm{LC}} \mathrm{K}_{\mathrm{d}} \mathrm{s}^{2}+\frac{\mathrm{V}_{\text {in }}}{\mathrm{LC}} \mathrm{K}_{\mathrm{p}} \mathrm{s}+\frac{\mathrm{V}_{\text {in }}}{\mathrm{LC}} \mathrm{K}_{\mathrm{i}}$ \\
\hline & $\left(\mathrm{s}^{3}+\left(\frac{1}{\mathrm{RC}}+\frac{\mathrm{V}_{\text {in }}}{\mathrm{LC}} \mathrm{K}_{\mathrm{d}}\right) \mathrm{s}^{2}+\left(\frac{1}{\mathrm{LC}}+\frac{\mathrm{V}_{\text {in }}}{\mathrm{LC}} \mathrm{K}_{\mathrm{p}}\right) \mathrm{s}+\left(\frac{\mathrm{V}_{\text {in }}}{\mathrm{LC}} \mathrm{xK}_{\mathrm{i}}\right)\right)$ \\
\hline
\end{tabular}

\subsection{Controller parameters}

The controller parameters of the conventional controller [15] are tuned based on root locus method. The roots are adjusted to satisfy the design requirements. Initially a $\mathrm{P}$ controller is designed and its performance is observed. It results in a steady state error and an oscillatory output but with a very fast rise time. Next, I controller was designed. It eliminated steady state error and oscillations but was a bit sluggish compared to P controller. Finally a PID controller was tuned to satisfy the desired objective. Its behavior was similar to I controller but a bit more sluggish in terms of rise time. Suitable values of gains are tuned to get the optimum output and result in good performance even in the presence of disturbances. Substituting the parameter values of buck converter and the controller, we arrive at the CLTF as given in Table 3.

Table 3: Controller parameters and TF of buck converter

\begin{tabular}{|l|c|}
\hline $\begin{array}{l}\text { Controller } \\
\text { Parameter }\end{array}$ & Closed Loop TF \\
\hline $\begin{array}{l}\mathrm{K}_{\mathrm{p}} \\
=0.8343\end{array}$ & $\frac{4.2136 \mathrm{e}^{8}}{\mathrm{~s}^{2}+1.5893 \mathrm{e}^{6} \mathrm{~s}+4.2136 \mathrm{e}^{8}}$ \\
\hline $\begin{array}{l}\mathrm{K}_{\mathrm{i}} \\
=2.1714\end{array}$ & $\frac{1.0967 \mathrm{e}^{9}}{\mathrm{~s}^{3}+1.5893 \mathrm{e}^{6} \mathrm{~s}^{2}+2.1044 \mathrm{e}^{-5} \mathrm{~s}+1.0967 \mathrm{e}^{9}}$ \\
\hline
\end{tabular}




\begin{tabular}{|l|c|}
\hline $\mathrm{K}_{\mathrm{d}}$ & \multicolumn{1}{|c|}{$6.6808 \mathrm{e}^{8}$} \\
$=9.2 \mathrm{e}^{-11}$ & $\frac{\mathrm{s}^{3}+1.5893 \mathrm{e}^{6} \mathrm{~s}^{2}+1.1111 \mathrm{e}^{5} \mathrm{~s}+6.6808 \mathrm{e}^{8}}{}$ \\
$\mathrm{~K}_{\mathrm{p}}$ & \\
$=2.2 \mathrm{e}^{-5}$ & \\
$\mathrm{~K}_{\mathrm{i}}$ & \\
$=1.3228$ & \\
\hline
\end{tabular}

\section{Simulation results}

4.

In this section, the effectiveness of 3 conventional control techniques are tested under 3 conditions namely reference voltage tracking, input voltage disturbance rejection and parameter disturbance rejection.

\subsection{Output voltage}

Fig. 5 Shows the output voltage waveform for the three conventions control techniques namely P, I \& PID. From the waveform, it is obvious that the designed $\mathrm{P}$ controller suffers from a steady state error of 0.55 . Also, we can see that the $P$ controller response is comparatively fast but suffers from huge overshoots and undershoots. Next, we take a look at the I controller response. The response has no overshoots and undershoots like the $\mathrm{P}$ controller response.

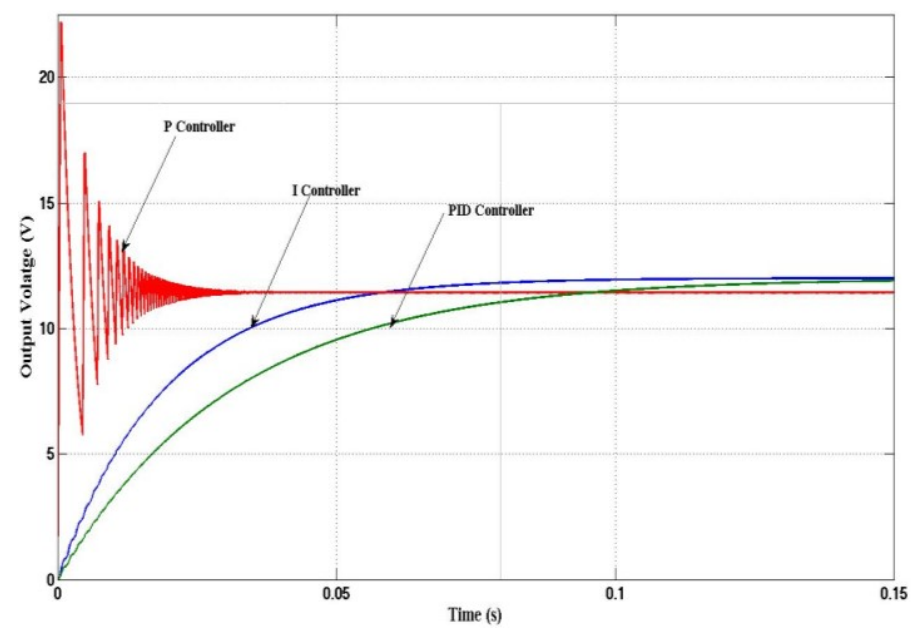

Fig. 5. Output voltage waveform

Also, the I controller response has zero steady state error. The third waveform shown in the figure belongs to the PID controller. The PID controller response has no overshoot and steady state error but a bit sluggish unlike I controller response.

\subsection{Reference voltage tracking}

In this section the reference voltage tracking ability of the conventional controllers are tested. Buck converter parameters are designed for a reference voltage requirement of $12 \mathrm{~V}$. In Fig. 6, the reference voltage is changed from $12 \mathrm{~V}$ to $13 \mathrm{~V}$ at $0.25 \mathrm{~s}$ and $13 \mathrm{~V}$ to $12 \mathrm{~V}$ at $0.6 \mathrm{~s}$. The response voltage is also shown in the figure for better understanding. From Fig. 6 it can be seen that $\mathrm{P}$ controller tracks the desired change in reference voltage faster compared to the other two control techniques though it suffers from oscillations initially. I and PID controllers provide accurate tracking of reference voltage without exhibiting any oscillations.

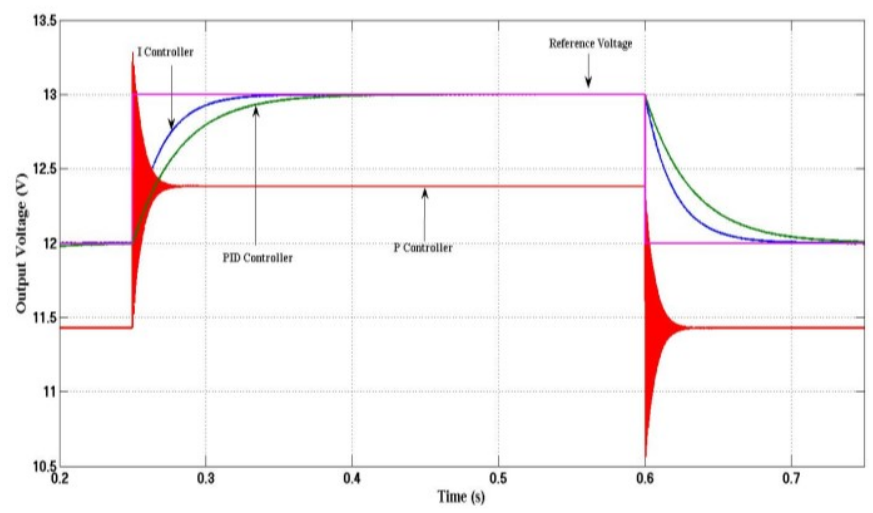

Fig. 6. Reference tracking waveform

\subsection{Input voltage disturbance rejection}

In Fig. 7 the disturbance rejection behavior of the conventional controller techniques for buck converter is given. Disturbances are introduced in the input voltage. A negative disturbance is introduced at $0.25 \mathrm{~s}$ and a positive disturbance at $0.6 \mathrm{~s}$. P controller response in the presence of input disturbance is robust in comparison with I and PID controllers. PID controller experiences an overshoot, undershoot of $0.48 \mathrm{~V}$ respectively and returns to the desired output voltage in $0.1 \mathrm{~s}$. Whereas I controller exhibits overshoot, undershoot of $0.25 \mathrm{~V}$ and returns to the nominal voltage in $0.05 \mathrm{~s}$.

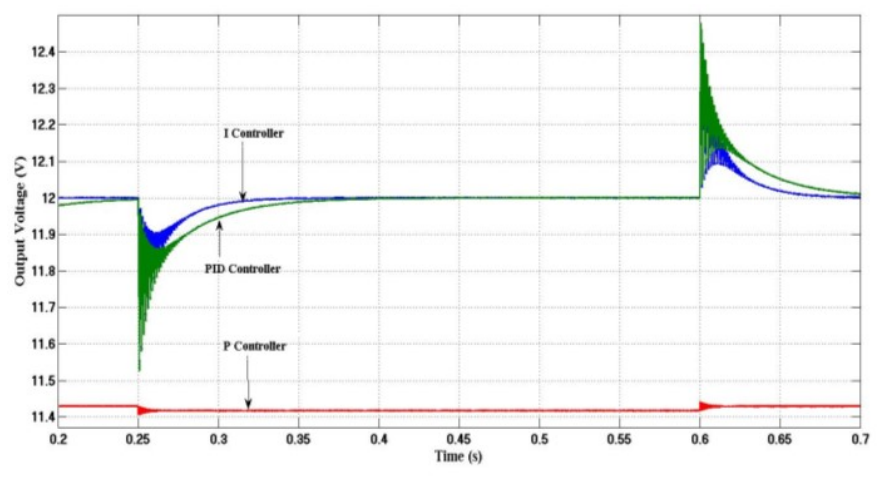

Fig. 7. Disturbance rejection waveform

\subsection{Parameter disturbance rejection}

In this section, parameter disturbance rejection properties of 
the 3 conventional control techniques are tested. Fig. 8 shows the parameter disturbance rejection waveform for a variation

in resistance $\mathrm{R}$ of the buck converter. The nominal resistance of the converter is $13 \mathrm{ohm}$. Here $+12.5 \%$ of disturbance is introduced in the resistance. From the figure, we can clearly see that I \& PID controllers exhibit no variation for changes in resistance and exhibit robust behavior. Whereas $P$ controller exhibits slight variation in output voltage overshoot and converges to the desired value in $0.02 \mathrm{~s}$.

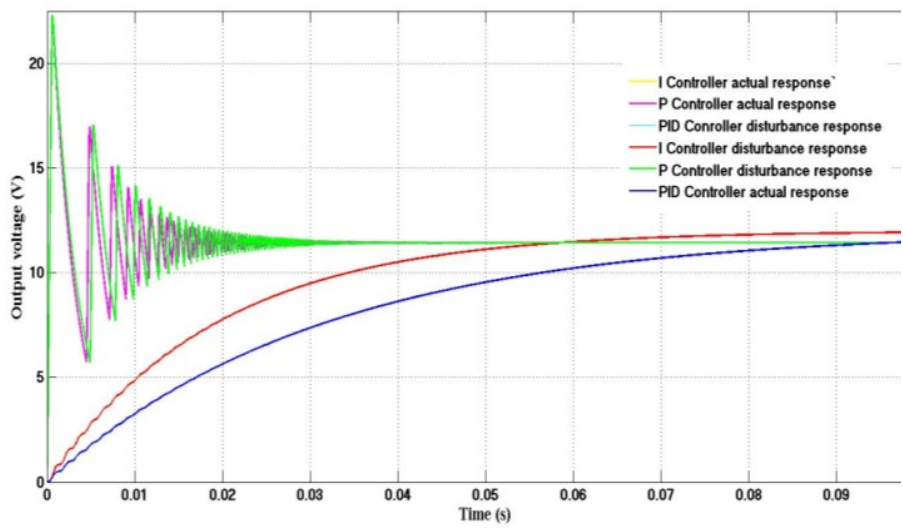

Fig. 8. Parameter disturbance rejection waveform

\section{Conclusion}

Derivation of three conventional control techniques for a buck converter is presented. A comparative study of the control techniques is given. Effectiveness of the conventional controller design is verified by means of simulation followed by analysis of the results in detail. It is concluded that PID and I control techniques provides an overall better response for regulation of voltage in a buck converter.

\section{References}

[1] A. Simon, \& O. Alejandro, Power switching converters (New York: CRC press, 2005).

[2] N. Mohan, T.M. Undeland, P. William, Power electronics converters application and design (Delhi, India: John wiley \& sons, 2009).

[3] W. Barry, "Basic DC to DC converters", IEEE transactions on power electronics, 23, 2008, 387401.
[4] E. Van Dijk, J.N. Spruijt, D.M. O’Sullivan, \& J.B. Klaassens, "PWM switch modeling of DC-DC converters", IEEE transactions on power electronics, 10, 1995, 659-665.

[5] W. Tasi Fu, \& C. Yu kai, "Modeling PWM DC-DC converters out of basic converter units", IEEE transactions on power electronics, 13, 1998, 870881.

[6] R.D. Middle Brook, "Small signal modeling of

[7] pulse width modulated switched mode power converters", Proceedings of the IEEE, 76, 1998, 343-354.

[8] S.C. Tan, Y.M. Lai, \& C.K. Tse, "General design issues of sliding mode controllers in DC DC converters", IEEE transactions on industrial electronics, 55, 2008, 1160-1174.

[9] X. Wei, K. Tsang, \& W. Chan, "DC-DC buck converter using internal model control", Electric power components and systems, 37, 2009, 320-330

[10] R. Naim, W. George, \& B. Sam, "H» control applied to boost converters", IEEE transactions on power electronics, 12, 1997, 677-683.

[11] A.J. Forsyth, I.K. Ellis, \& M. Moller, "Adaptive control of a high frequency DC-DC converter by parameter scheduling", IEEE proceedings on electrical power applications, 146, 1999, 447-454.

[12] G.B. Andrea, M. Sebastien, C. Sebastien, S. Wang, \& M. Morari, "Explicit model predictive control of DC-DC switched mode power supplies with extended kalman filtering", IEEE transactions on industrial electronics, 56, 2009, 1864-1874.

[13] S. Uran, \& M. Milanovic, "Advanced control of buck converter", Proc. IEEE International conference on industrial technology, 2003, 602607.

[14] R. Shama, \& S.K. Patnaik, "Implementation of dual loop controller for positive output elementary Luo converter", IET power electronics, 6, 2013, 885893.

[15] R. Shama, K. Vutukuru, \& S.K. Patnaik, "SM based IMC-PID control of single switch quadratic boost converter for wide DC conversion ratios", Electric power components and systems, 41, 2013, 1617-1634.

[16] J.C. Stephen, MATLAB programming for engineers (Australia: 2010). 